\title{
Long-term thyroxine administration increases heat stress protein-70 mRNA expression and attenuates p38 MAP kinase activity in response to ischaemia
}

\author{
C I Pantos, V A Malliopoulou, I S Mourouzis, E P Karamanoli, \\ S M Tzeis, H C Carageorgiou, D D Varonos and D V Cokkinos ${ }^{1}$ \\ Department of Pharmacology, University of Athens, 75 Mikras Asias Avenue, 11527 Goudi, Athens, Greece \\ ${ }^{1}$ First Cardiology Department, Onassis Cardiac Surgery Centre, 356 Sygrou Avenue, 17674 Kallithea, Athens, Greece \\ (Requests for offprints should be addressed to C I Pantos; Email: cpantos@cc.uoa.gr)
}

\begin{abstract}
The present study was undertaken to investigate heat stress protein (HSP)-70 mRNA induction and p38 MAP kinase (MAPK) activity in response to ischaemic stress in the hyperthyroid rat heart.

L-Thyroxine $\left(\mathrm{T}_{4}\right) \quad(25 \mu \mathrm{g} / 100 \mathrm{~g}$ body weight $)$ was administered to Wistar rats for 2 days (THYRacute) or 14 days (THYR), while animals treated similarly with normal saline served as controls (NORMacute and NORM). In addition, abdominal aortic banding was performed in another group of rats to produce constriction-induced hypertrophy (HYP), while sham-operated (SOP) animals served as controls. Isolated rat hearts were perfused in a Langendorff mode. Hearts from NORMacute $(n=6)$, THYRacute animals $(n=8)$, NORM $(n=6)$, THYR $(n=6)$, SOP $(n=5)$ and HYP $(n=7)$ animals were subjected to $20 \mathrm{~min}$ of zero-flow global ischaemia followed by $45 \mathrm{~min}$ of reperfusion. HSP70 mRNA expression and phosphorylated p38 MAPK protein expression were detected in response to ischaemia and protein kinase $\mathrm{C}-\varepsilon(\mathrm{PKC} \varepsilon)$ protein expression was detected at baseline. Thyroid hormones were measured in plasma.

Long-term $\mathrm{T}_{4}$ administration and aortic constriction resulted in the development of cardiac hypertrophy.
\end{abstract}

Thyroid hormones were increased in both THYR and THYRacute as compared with normal groups $(P<0 \cdot 05)$. HSP70 mRNA induction was increased 2.3-fold in THYR as compared with NORM hearts $(P<0 \cdot 05)$, whereas there was not any difference between THYRacute and NORMacute hearts $(P>0 \cdot 05)$. Phosphorylated p38 MAPK protein expression was $2 \cdot 2$-fold more in NORM than in THYR hearts $(P<0 \cdot 05)$, but it was not different between NORMacute and THYRacute hearts $(P>0 \cdot 05)$. HSP70 mRNA induction was $1 \cdot 8$-fold greater in HYP than in SOP hearts $(P<0 \cdot 05)$, whereas phosphorylated $\mathrm{p} 38$ MAPK protein expression was similar between the two groups $(P>0 \cdot 05)$. PKC $\varepsilon$ protein expression at baseline was $1 \cdot 7$-fold more in NORM than in THYR hearts $(P<0 \cdot 05)$, and not different between NORMacute and THYRacute hearts $(P>0 \cdot 05)$ as well as HYP and SOP hearts $(P>0 \cdot 05)$.

This study shows that HSP70 mRNA expression is increased, whereas p38 MAPK activation is attenuated in response to ischaemia in long-term $\mathrm{T}_{4}$-treated rat hearts as compared with normal and acute hyperthyroid hearts.

Journal of Endocrinology (2001) 170, 207-215

\section{Introduction}

Hyperthyroidism is associated with various effects on the myocardium that could potentially render the heart less tolerant to ischaemic stress. In hyperthyroidism, cardiac hypertrophy develops and alterations in cardiac energy metabolism occur (Klein 1980, Polikar et al. 1993). In fact, hearts with L-thyroxine $\left(\mathrm{T}_{4}\right)$-induced cardiac hypertrophy has been found to have a shift towards isomyosin V1, the myosin with the fast ATPase activity and consequently decreased thermodynamic efficiency (Hoh \& Egerton 1979). Furthermore, the levels of creatinine, phospho- creatine, ATP and glycogen are reduced in hyperthyroid hearts (Van der Vusse et al. 1998). However, hearts from $\mathrm{T}_{4}$-treated animals are reported to tolerate ischaemia as well as normal hearts or even better, but the exact mechanism of this response is unclear (Buser et al. 1990, Pantos et al. 1999, 2000).

The adaptive response of the hyperthyroid heart to ischaemia and its molecular basis have not been adequately studied. It is likely that the occurring functional and metabolic changes in the hyperthyroid heart can induce changes in gene expression of various molecules that can confer cardioprotection against ischaemic insult. Heat 
stress proteins (HSPs) and intracellular mitogen-activated protein kinases (MAPKs) have been found to play an essential role in the adaptive response of the normal heart to ischaemia (Gray et al. 1999, Bogoyevitch 2000). In fact, ischaemia can lead to the induction of HSPs and activation of the intracellular kinases as a cellular response to stress. HSP70, a member of the HSP family, has been associated with preservation of high energy phosphates, antiapoptotic effects and increased tolerance to ischaemic stress (Gray et al. 1999). p38 MAPK, a member of the MAPK family, has been shown to be activated in response to ischaemia and to be one of the signal transducers of apoptosis (Zechner et al. 1998, Yaoita et al. 2000). Furthermore, inhibition of p38 MAPK is associated with reduced apoptosis (Zechner et al. 1998, Ma et al. 1999) and increased post-ischaemic functional recovery (Ma et al. 1999). Similar studies on hyperthyroid hearts do not appear in the current literature. However, in those hearts, the study of the pattern of HSP70 mRNA expression and p38 MAPK activation in response to ischaemia could be of importance, since hyperthyroid hearts seem to have an increased tolerance to ischaemia through an undefined mechanism (Buser et al. 1990, Pantos et al. 1999, 2000).

The present study was designed to investigate the pattern of HSP70 mRNA expression and p38 MAPK activation in response to ischaemia in isolated hyperthyroid rat hearts. In addition, in order to define the role of cardiac hypertrophy per se in that particular response, the expression of HSP70 mRNA and the activation of p38 MAPK were also assessed in another model of cardiac hypertrophy, the aortic banding-induced cardiac hypertrophy (HYP).

\section{Materials and Methods}

\section{Animals}

Seventy-four Wistar male rats, 280-320 g body weight (BW), were used for this study. The rats were handled in accordance with the Guide for the Care and Use of Laboratory Animals published by the US National Institutes of Health (NIH Publication No. 85-23, revised 1985). Anaesthesia was achieved with i.p. injection of ketamine hydrochloric acid $(150 \mathrm{mg} / \mathrm{kg})$.

\section{$\mathrm{T}_{4}$ administration}

Hyperthyroidism was induced in rats by $\mathrm{T}_{4}$ administration. $\mathrm{T}_{4}$ (Sigma Chemicals, St Louis MO, USA) was dissolved in $99 \%$ ethanol by adding a small volume $(20 \mu \mathrm{l})$ of $25 \%$ $\mathrm{NaOH}$ and diluted 33-fold by adding $0.9 \% \mathrm{NaCl}$ to obtain a stock solution of $1 \mathrm{mg} / \mathrm{ml}$. Before each injection a fresh solution was made in $0.9 \% \mathrm{NaCl}$ to a concentration of $50 \mu \mathrm{g} \mathrm{T} \mathrm{T}_{4} / \mathrm{ml} \mathrm{T}_{4}(25 \mu \mathrm{g} / 100 \mathrm{~g} \mathrm{BW})$ was administered s.c. once daily for 14 days. This treatment results in long-term moderate hyperthyroidism (Grofte et al. 1997). Normal rats were treated with s.c. injections of normal saline given once daily for 14 days (Pantos et al. 1999, 2001).

$\mathrm{T}_{4}$ and normal saline were also administered once daily for 2 days and this treatment has been shown to result in acute hyperthyroidism (Grofte et al. 1997, Pantos et al. 2000).

\section{Abdominal aortic stenosis}

Abdominal aortic stenosis was induced using Weck haemoclips (Pilling Medical, Le Faget, France) placed above the renal arteries near the diaphragm using modified Weck Forceps. The diameter of the clips was calibrated to produce cardiac hypertrophy with a reasonably low mortality (approximately 15\%). A moderate hypertrophy was obtained after 4 weeks in most animals. Sham-operated (SOP) animals served as controls (Pantos et al. 1996).

\section{Isolated heart preparation}

A non-ejecting isolated rat heart preparation was perfused at a constant flow according to the Langendorff technique. An intraventricular balloon allowed measurement of contractility under isovolumic conditions. Left ventricular balloon volume was adjusted to produce an average initial left ventricular end-diastolic pressure (LVEDP) of $6 \mathrm{mmHg}$ in all groups and was held constant thereafter throughout the experiment. Since the balloon was not compressible, left ventricular contraction was isovolumic. As intraventricular volume was maintained at a constant value, diastolic fibre length, which represented preload, did not change. Thus, the left ventricular peak systolic pressure and the left ventricular developed pressure (LVDP), defined as the difference between left ventricular peak systolic pressure and LVEDP, represented contractility indexes obtained under isometric conditions.

Rats were anaesthetized with ketamine hydrochloric acid, and heparin $(1000 \mathrm{IU} / \mathrm{kg})$ was given i.v. before thoracotomy. The hearts were rapidly excised, placed in ice-cold Krebs-Henseleit buffer (composition in $\mathrm{mM}$ : sodium chloride 118 , potassium chloride $4 \cdot 7$, potassium phosphate monobasic $1 \cdot 2$, magnesium sulphate $1 \cdot 2$, calcium chloride $1 \cdot 4$, sodium bicarbonate 25 and glucose 11 ) and mounted on the aortic cannula of the Langendorff perfusion system. Perfusion with oxygenated $\left(95 \% \mathrm{O}_{2} /\right.$ $\left.5 \% \mathrm{CO}_{2}\right)$ Krebs-Henseleit buffer was established within $60 \mathrm{~s}$ after thoracotomy. The perfusion apparatus was heated to ensure a temperature of $37{ }^{\circ} \mathrm{C}$ throughout the experiment. Hearts were paced at 320 beats/min with a Harvard pacemaker (Edenbridge, Kent, UK). The pacemaker was turned off during the period of ischaemia. The water-filled balloon, connected to a pressure transducer and coupled to a Gould RS 3400 recorder (Valley View, 
$\mathrm{OH}, \mathrm{USA}$ ) was advanced into the left ventricle through an incision in the left atrium (Pantos et al. 1996, 1999, 2000).

\section{Isolation of RNA and Northern blot analysis}

Total RNA was extracted from myocardial ventricular tissue according to the procedure described by Chomczynsky \& Sacchi (1987). The concentration of RNA was estimated by measuring the optical density (OD) of the preparation at $260 \mathrm{~nm}$. The ratio of the readings at $260 \mathrm{~nm}$ and $280 \mathrm{~nm}$ provided the estimate of the purity of the isolated RNAs. The isolated RNAs had ratios between 1.8 and $2 \cdot 0$. Twenty micrograms of RNA from each sample were subjected to $1 \%$ agaroseformaldehyde gel electrophoresis and then transferred to a nylon membrane (Amersham, Little Chalfont, Bucks, UK) by capillary blot. The membranes were baked at $80{ }^{\circ} \mathrm{C}$ for $2 \mathrm{~h}$. Hybridization was carried out at $65^{\circ} \mathrm{C}$ for $18 \mathrm{~h}$ using human HSP70 cDNA probe labelled with fluorescein11-dUTP and the random prime labelling module (Amersham). The membranes were washed using a solution of $1 \times \mathrm{SSC}-0 \cdot 1 \% \mathrm{SDS}$ at $65^{\circ} \mathrm{C}$ for $15 \mathrm{~min}$ followed by a wash at $65^{\circ} \mathrm{C}$ in $0 \cdot 1 \times \mathrm{SSC}-0 \cdot 1 \%$ SDS for 15 min. The Gene Images CDP-Star detection module (Amersham) was used for detection. The autoradiograph was established by exposing the membrane for about 20 min to Hyperfilm-ECL film (Amersham). Blots were rinsed by stripping and rehybridized with GAPDH cDNA probe for internal control of the quantity of total RNA. Autoradiographs were quantified by a scanning densitometer (Alpha Scan Image Densitometer; Alpha Innotech Corporation, San Leandro, CA, USA) and the strength of the message was presented as the ratio of HSP70 mRNA relative to GAPDH mRNA expression.

\section{Total protein preparation}

Approximately $0.3 \mathrm{~g}$ frozen tissue was homogenized in ice-cold Tris-sucrose buffer $(0.35 \mathrm{M}$ sucrose, $10 \mathrm{mM}$ Tris- $\mathrm{HCl} \mathrm{pH}$ 7.5, $1 \mathrm{mM}$ EDTA, 0.5 mM dithiothreitol, $0.1 \mathrm{mM}$ polymethylsulphonyl fluoride) with an Ultra Turrax T25 (Fisher Bioblock, Illkirch, France) homogenizer and the resulting homogenate was centrifuged at $15000 \mathrm{~g}$ for $20 \mathrm{~min}$ at $4{ }^{\circ} \mathrm{C}$. The supernatant, representing the total cell extract, was used for immunoblotting. Protein concentrations were determined by the bicinchoninic acid method using BSA as a standard (Walker 1994).

\section{SDS-PAGE and immunoblotting}

The supernatants were prepared for SDS-PAGE by boiling for $5 \mathrm{~min}$ in Laemmli sample buffer containing 5\% 2 -mercaptoethanol. Protein aliquots $(40 \mu \mathrm{g})$ were loaded onto $10 \%(\mathrm{w} / \mathrm{v})$ acrylamide gels and subjected to SDSPAGE in a Bio-Rad (Hercules, CA, USA) Mini Protean gel apparatus. For visualization of proteins, gels were stained in $0.3 \%(\mathrm{w} / \mathrm{v})$ Coomassie Brilliant Blue R250 in 40\% (v/v) methanol, 7\% (v/v) glacial acetic acid and destained in the same solution without Coomassie Blue. For Western blotting following SDS-PAGE, proteins were transferred electrophoretically to nitrocellulose membrane (Hybond ECL; Amersham) at $250 \mathrm{~mA}$ and $4{ }^{\circ} \mathrm{C}$ using Towbin buffer. Following transfer, the nitrocellulose membrane was blocked by incubation in $5 \%(\mathrm{w} / \mathrm{v})$ non-fat dry milk dissolved in Tris-buffered saline-Tween 20 (TBST) for $1 \mathrm{~h}$ at room temperature. Blots were washed in TBST $(3 \times 5 \mathrm{~min})$. Filters were then incubated with either protein kinase- $\varepsilon$ (PKC $\varepsilon$ ) antibody (Transduction Laboratories, Lexington, KY, USA), dual phosphorylated p38 MAPK antibody or p38 MAPK antibody (New England Biolabs, Hitchin, Herts, UK) (dilution 1:1000) overnight at $4{ }^{\circ} \mathrm{C}$. Blots were washed in TBST $(3 \times 5 \mathrm{~min})$ and then exposed to horseradish peroxidaseconjugated second antibody at a dilution of 1:2000 for $1 \mathrm{~h}$ at room temperature. Filters were washed as above, incubated with ECL reagents and exposed to Hyperfilm paper (Amersham). Immunoblots and gels were quantified using the AlphaScan Imaging Densitometer (Alpha Innotech). Sample loadings were equalized relative to the $\mathrm{OD}$ of the actin band. ODs of PKCE, dual phosphorylated p38 and p38 MAPK immunoreactivity were expressed as a ratio of the actin OD to correct for slight variations in total protein loading.

\section{Experimental protocol}

Hearts from normal, acute and long-term $\mathrm{T}_{4}$-treated animals, SOP and HYP animals that had not been subjected to any experimental procedure were used for the measurement of the PKCE levels at baseline.

In order to detect the baseline HSP70 mRNA expression, hearts from all groups were perfused without being subjected to any ischaemic insult for a period equal to the duration of the experimental protocol.

Hearts from normal, hyperthyroid, SOP and HYP animals underwent an initial 30 min stabilization period. They were then subjected to $20 \mathrm{~min}$ of zero-flow global ischaemia followed by $45 \mathrm{~min}$ of reperfusion. Thus, there were the following experimental groups; hearts from normal animals with 2 day normal saline administration (NORMacute, $n=6$ ), hearts from hyperthyroid animals with 2 day $\mathrm{T}_{4}$ administration (THYRacute, $n=8$ ), hearts from normal animals with 14 day normal saline administration (NORM, $n=6$ ), hearts from hyperthyroid animals with 14 day $\mathrm{T}_{4}$ administration (THYR, $n=6$ ), hearts from SOP animals, $(n=5)$, and hearts from HYP animals $(n=7)$.

\section{Measurement of thyroid hormones}

Plasma $\quad \mathrm{T}_{4}$ and tri-iodothyronine $\left(\mathrm{T}_{3}\right)$ quantitative measurements were performed by using ${ }^{125}$ I RIA kits 
obtained from DiaSorin, Stillwater, MN, USA (CA $1535 \mathrm{M}$ for $\mathrm{T}_{4}$ and CA 1541 for $\mathrm{T}_{3}$ ). $\mathrm{T}_{4}$ and $\mathrm{T}_{3}$ levels were expressed as $\mathrm{pmol} / \mathrm{ml}$ plasma.

\section{Measurement of cardiac hypertrophy}

Cardiac hypertrophy was assessed by the measurement of left ventricular weight (LVW, in $\mathrm{mg}$ ) and the ratio of LVW to BW (in g) (LVW/BW, in $\mathrm{mg} / \mathrm{g}$ ).

\section{Measurement of mechanical function}

Left ventricular systolic function was assessed by recording LVDP at the end of the stabilization period and at $45 \mathrm{~min}$ of reperfusion. Post-ischaemic function was assessed by the recovery of LVDP, which was expressed as per cent of the initial value (LVDP\%). Diastolic function was assessed by monitoring isovolumic LVEDP as a measure of diastolic chamber distensibility. LVEDP was measured at $45 \mathrm{~min}$ of reperfusion (LVEDP45).

\section{Statistics}

Values are presented as means \pm S.E.M. An unpaired $t$-test and a Mann-Whitney test were used for differences between groups. A two-tailed test with a $P$ value less than $0 \cdot 05$ was considered significant.

\section{Results}

Cardiac hypertrophy

In acute hyperthyroidism, LVW was $887 \cdot 8 \pm 33.5 \mathrm{mg}$ for NORMacute and $882.6 \pm 33.1 \mathrm{mg}$ for THYRacute hearts $(P>0 \cdot 05)$. LVW/BW was $2 \cdot 5 \pm 0.06$ for NORM acute and $2 \cdot 6 \pm 0.10$ for THYRacute hearts $(P>0 \cdot 05)$. With long-term $\mathrm{T}_{4}$ administration, LVW was increased in THYR as compared with normal hearts $(1108 \pm 46 \cdot 8$ vs $872 \cdot 2 \pm 23 \cdot 3 \mathrm{mg}, P<0 \cdot 05)$. LVW $/ \mathrm{BW}$ was $2 \cdot 5 \pm 0 \cdot 10$ for NORM and $3 \cdot 1 \pm 0 \cdot 09$ for THYR hearts $(P<0 \cdot 05)$.

LVW was $909.5 \pm 25.5 \mathrm{mg}$ for SOP and $988.2 \pm$ $23.8 \mathrm{mg}$ for HYP hearts $(P<0 \cdot 05)$. LVW/BW was $2 \cdot 8 \pm 0.06$ for HYP and $2 \cdot 5 \pm 0.04$ for SOP hearts $(P<0 \cdot 05)$.

\section{Thyroid hormones}

$\mathrm{T}_{4}$ administration resulted in increased thyroid hormone levels in the blood. $\mathrm{T}_{4}$ and $\mathrm{T}_{3}$ were $47 \cdot 1 \pm 6 \cdot 0$ and $0 \cdot 8 \pm 0 \cdot 1 \mathrm{pmol} / \mathrm{ml}$ for NORM animals, $1041 \cdot 3 \pm 69 \cdot 8$ and $6 \cdot 0 \pm 0.9 \mathrm{pmol} / \mathrm{ml}$ for THYRacute animals $(P<0 \cdot 05)$ and $723 \cdot 2 \pm 79 \cdot 2$ and $7 \cdot 4 \pm 0 \cdot 9 \mathrm{pmol} / \mathrm{ml}$ for THYR animals $(P<0 \cdot 05)$.
Table 1 Left ventricular developed pressure at the end of the stabilization period (LVDP), left ventricular end-diastolic pressure at 45 min of reperfusion (LVEDP45) and recovery of left ventricular developed pressure (LVDP\%) in normal (NORMacute and NORM), hyperthyroid hearts (THYRacute and THYR), hearts from sham-operated (SOP) and aortic-banded (HYP) rats. The values are means (S.E.M.)

\begin{tabular}{|c|c|c|c|c|}
\hline & $n$ & LVDP & LVEDP45 & LVDP\% \\
\hline $\begin{array}{l}\text { Group } \\
\text { NORMacute }\end{array}$ & 6 & $115.6(1.9)$ & $59 \cdot 6(7 \cdot 1)$ & $54 \cdot 8(5 \cdot 0)$ \\
\hline THYRacute & 8 & $113 \cdot 5(5 \cdot 1)$ & $49 \cdot 2(4 \cdot 2)$ & $59 \cdot 7(4 \cdot 3)$ \\
\hline NORM & 6 & $110 \cdot 7(5 \cdot 4)$ & $66.0(5 \cdot 8)$ & $37 \cdot 2(4 \cdot 5)$ \\
\hline THYR & 6 & $127 \cdot 6(2 \cdot 3)^{*}$ & $53.3(8.5)$ & $54.9(5.5)^{*}$ \\
\hline SOP & 5 & $97 \cdot 6(3 \cdot 4)$ & $54 \cdot 8(6 \cdot 6)$ & $53 \cdot 3(5 \cdot 8)$ \\
\hline HYP & 7 & $132 \cdot 6(5 \cdot 6)^{* *}$ & $60 \cdot 6(9.9)$ & $43 \cdot 4(8 \cdot 2)$ \\
\hline
\end{tabular}

${ }^{*} P<0.05$ vs NORM; ${ }^{* * P<0.05}$ vs SOP.

\section{Parameters of cardiac function}

LVDP at the end of the stabilization period, LVEDP45 and LVDP\% for all groups are shown in Table 1.

\section{HSP70 mRNA expression at baseline and after ischaemia}

HSP70 mRNA expression was not detected at baseline in hearts from any of the experimental groups.

The induction of HSP70 mRNA by ischaemia was $2 \cdot 3$-fold greater in THYR as compared with NORM hearts $(P<0 \cdot 05)$, but there was no statistically significant difference between the THYRacute and NORMacute hearts $(P>0 \cdot 05)$, (Figs 1 and 2 ). The induction of HSP70 mRNA by ischaemia was $1 \cdot 8$-fold greater in HYP as compared with SOP hearts, $(P<0 \cdot 05)$ (Figs 1 and 2$)$.

Phosphorylated p38 MAPK protein expression in response to ischaemia

Phosphorylated p38 MAPK protein expression was $2 \cdot 2$-fold more in NORM than in THYR hearts $(P<0 \cdot 05)$, but it was not different between NORMacute and

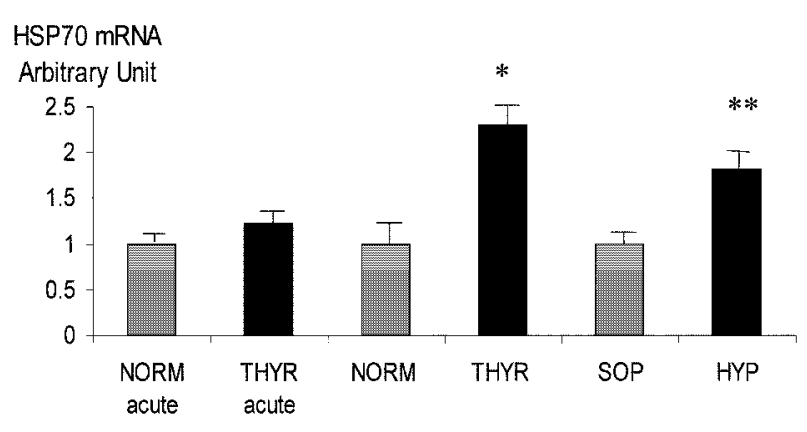

Figure 1 Densitometric assessment of Northern blots showing the expression of HSP70 mRNA induced by ischaemia in hyperthyroid (THYRacute and THYR) and normal hearts (NORMacute and NORM), and hearts from SOP and HYP rats (columns are means of $\mathrm{OD}$ ratios+S.E.M.). ${ }^{*} P<0 \cdot 05$ vs NORM, ${ }^{* *} P<0 \cdot 05$ vs SOP. 

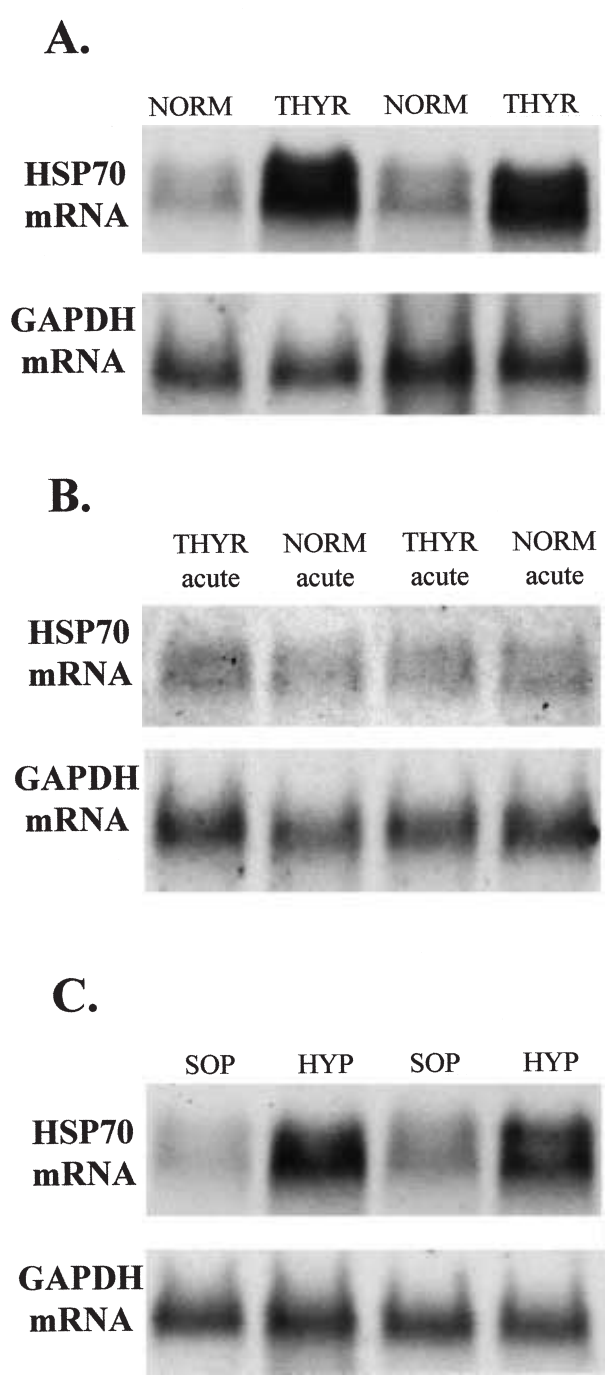

Figure 2 Northern blots showing the expression of HSP70 mRNA induced by ischaemia in (A) hearts from THYR and NORM rats; (B) hearts from THYRacute and NORMacute rats; and (C) hearts from SOP and HYP rats.

THYRacute hearts, $(P>0 \cdot 05)$ (Fig. 3). Phosphorylated p38 MAPK protein expression was not different between HYP and SOP hearts $(P>0 \cdot 05)$ (Fig. 3).

\section{PKCE protein expression at baseline}

$\mathrm{PKC} \varepsilon$ protein expression at baseline was $1 \cdot 7$-fold more in NORM than in THYR hearts $(P<0 \cdot 05)$ and not different between NORMacute and THYRacute hearts $(P>0 \cdot 05)$ (Fig. 4). In addition, PKCE protein expression at baseline was not different between SOP and HYP hearts $(P>0 \cdot 05)$ (Fig. 4).

\section{Discussion}

In this study we investigated the expression of HSP70 mRNA and the activation of p38 MAPK in response to ischaemia in hyperthyroid rat hearts. These molecules are involved in the biochemical pathways that allow adaptation of the cell to various stresses such as ischaemia, hypoxia or heat.

HSP70 mRNA induction has been found to occur in normal hearts in response to ischaemia. Oxidant stress, intracellular ATP depletion and anaerobic metabolism by itself have been found to activate the heat shock transcription factor and increase the expression of HSP70 in response to ischaemic stress (Benjamin et al. 1992, Kukreja et al. 1994, Myrmel et al. 1994). Furthermore, this response can be modulated by various factors such as cardiac hypertrophy, ageing and neurohormonal alterations that accompany certain disease states (Nitta et al. 1994, Tajima et al. 1997). In fact, in an in vivo model of pressure overload cardiac hypertrophy, HSP70 mRNA expression in response to brief regional ischaemia was found to be attenuated in hypertrophied as compared with normal hearts, while a longer period of ischaemia abolished that response (Tajima et al. 1997). Furthermore, in ageing hearts, HSP70 mRNA induction by ischaemia was also shown to be attenuated in comparison with young hearts (Nitta et al. 1994).

In the present study, HSP70 mRNA induction in response to ischaemia was found to be altered in the presence of thyroid hormone excess. In fact, HSP70 mRNA induction was increased in hearts from THYR animals as compared with NORM hearts. Neurohormonal and other cellular changes that occur in hyperthyroidism can account for this response. Increased circulating thyroid hormone levels and/or the development of cardiac hypertrophy may play an essential role (Pantos et al. 1999, 2000). In order to address this issue, a model of acute hyperthyroidism was established and another model of cardiac hypertrophy was studied. In the model of acute hyperthyroidism, as it has been previously described, cardiac hypertrophy does not develop, but the circulating thyroid hormones are elevated to similar levels as in long-term administration of $\mathrm{T}_{4}$. Interestingly, in this experimental setting, we found that HSP70 mRNA induction by ischaemia was similar in THYRacute and NORMacute hearts. Hearts from HYP rats overexpressed HSP70 mRNA in response to ischaemia as compared with hearts from SOP rats. These data probably indicate that the development of cardiac hypertrophy rather than the increased levels of thyroid hormones might play an important role in the increased induction of HSP70 mRNA after sustained global ischaemia. However, the underlying mechanism of this response remains undefined. In cardiac hypertrophy, increased activation of various transcription factors has been shown to occur (Moalic et al. 1989). It is likely that such changes could alter the pattern of HSP70 


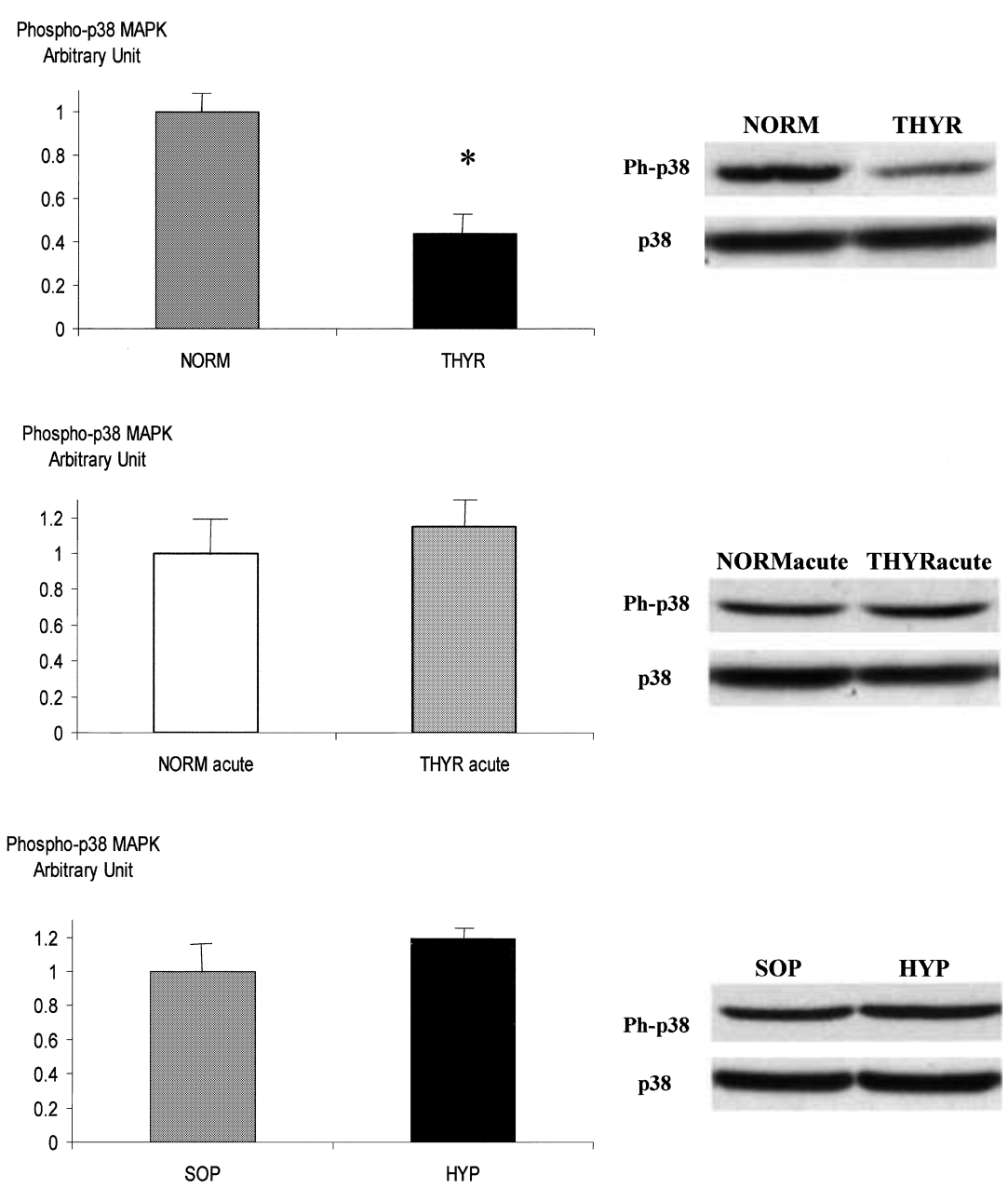

Figure 3 Phosphorylated p38 MAPK protein expression in hearts from THYRacute, THYR, NORMacute, NORM, SOP and HYP rats. Phosphorylated p38 MAPK was detected as a 40 kDa band. Ph-p38= phosphorylated p38 MAPK, p38=total p38 MAPK (columns are means of $\mathrm{OD}$ ratios + S.E.M.). ${ }^{\star} P<0 \cdot 05$ vs NORM.

mRNA induction by ischaemia in the hyperthyroid hearts.

The present study has also investigated the mode of p38 MAPK activation in the hyperthyroid heart subjected to ischaemic stress. p38 MAPK is one of the intracellular MAPKs that has been shown to be activated after ischaemia in normal hearts and the activation is maintained during the reperfusion period (Bogoyevitch et al. 1996, Yin et al. 1997). Both the duration and intensity of the stress seem to determine its regulation and the final cellular outcome (Mackay \& Mochly-Rosen 1999, Bogoyevitch 2000). Transient activation of p38 MAPK seems not to have a deleterious effect on the cell, whereas sustained activation of p38 MAPK induces apoptosis (Mackay \& Mochly-Rosen 1999). Activation of p38 MAPK has been found to promote cardiac myocyte death during extended periods of ischaemia (Mackay \& Mochly-Rosen 1999), whereas inhibition of p38 MAPK can reduce apoptosis (Zechner et al. 1998, Ma et al. 1999) and delay ischaemic cell death (Mackay \& Mochly-Rosen 1999, Barancik et al. 2000). In humans, it is also reported that the activity of p38 MAPK is increased in heart failure secondary to ischaemic heart disease (Cook et al. 1999). Furthermore, Nagarkatti \& Shaafi (1998) by using either SB203580, an inhibitor of p38 MAPK, or $\mathrm{G}_{0} 6850$, an inhibitor of PKC, during a lethal ischaemic insult, demonstrated increased cell survival as compared with cells subjected directly to the insult and suggested that this protective response involves both PKC and p38 MAPK.

In this study, we measured the levels of the dual phosphorylated p38 MAPK to assess the activity of p38 MAPK in response to ischaemia. It is known that p38 MAPK is activated by dual phosphorylation of threonine 180 and tyrosine 182 (Nagarkatti \& Shaafi 1998). In 

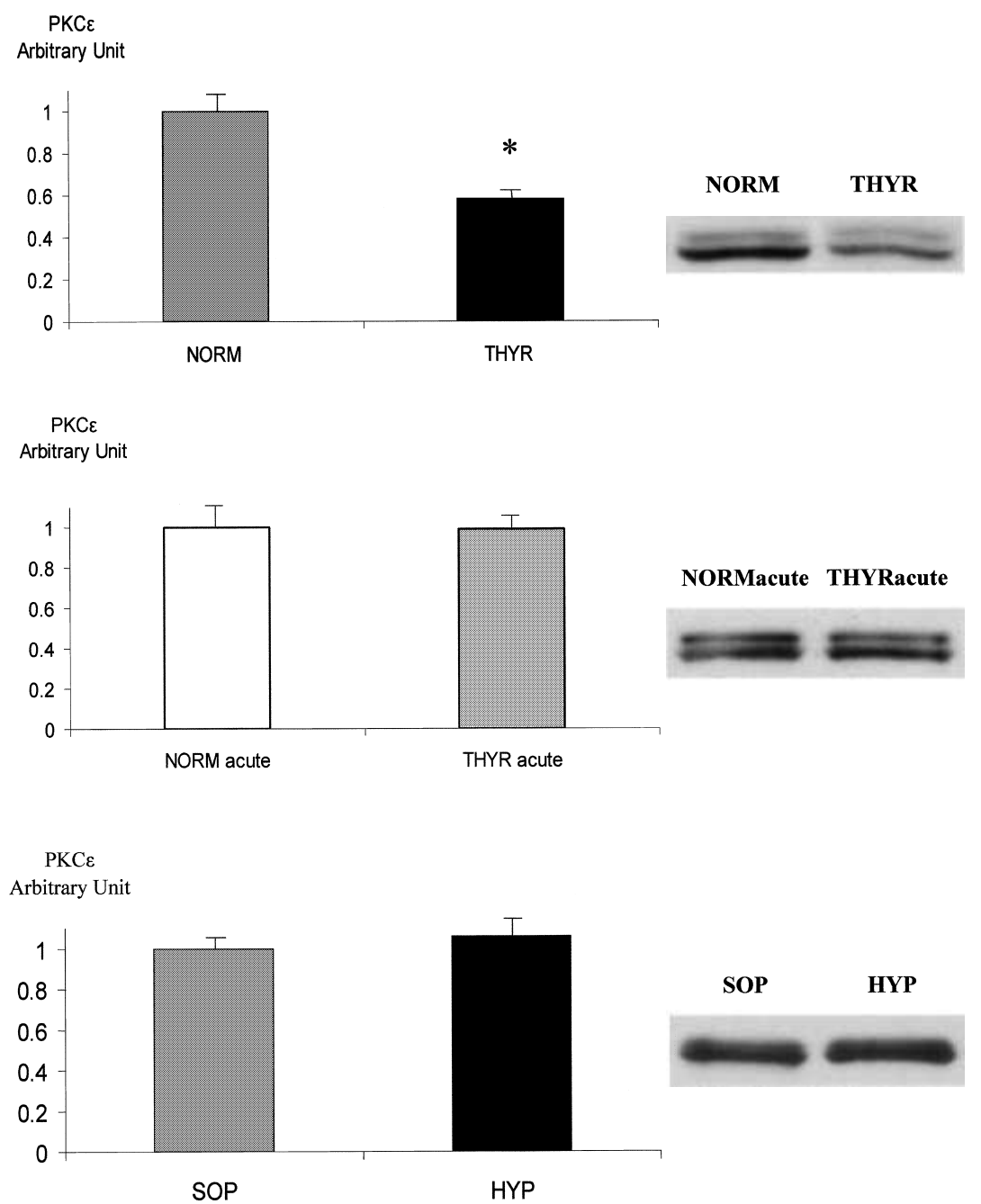

Figure 4 PKCE protein expression in hearts from THYRacute, THYR, NORMacute, NORM, SOP and HYP rats. PKCE was detected as a $90 \mathrm{kDa}$ band (columns are means of OD ratios+S.E.M.). ${ }^{*} P<0.05$ vs NORM.

THYR hearts, dual phosphorylated p38 MAPK after ischaemia was less as compared with NORM hearts. Furthermore, in the experimental setting of the acute hyperthyroidism, this response was abolished. In fact, the levels of the phosphorylated p38 MAPK after ischaemia were similar in THYRacute and NORMacute hearts.

These data suggest that the observed reduction in p38 MAPK activity in response to ischaemia in hearts with chronic $\mathrm{T}_{4}$ treatment is probably the result of the development of cardiac hypertrophy per se. However, as our data show, a similar response was not observed in hearts from HYP rats. Indeed, phosphorylated p38 MAPK levels in response to ischaemia were similar in hearts from HYP as compared with hearts from SOP animals. This observation probably indicates that the decreased p38 MAPK

www.endocrinology.org activation that occurs after ischaemia in long-term $\mathrm{T}_{4^{-}}$ treated hearts cannot be merely attributed to cardiac hypertrophy per se and other factors might also be involved. In fact, recent studies show that in hearts with different types of cardiac hypertrophy, various alterations exist in the intracellular PKC (Fryer et al. 1998, Jalili et al. 1999, Hamasaki et al. 2000), a molecule that has been previously demonstrated to be involved as well as p38 MAPK in the intracellular signalling transduction pathway that mediates the adaptive response of the cardiac cell to ischaemic stress (Nagarkatti \& Shaafi 1998).

Interestingly, Fryer et al. (1998) found that the expression of the $\varepsilon$-isoform of PKC was decreased in hyperthyroid hearts and this modulation of the PKCE isoform was suggested to be a specific response to an activated renin-angiotensin system. Furthermore, Hamasaki et al. 
(2000) in experimental models of $\mathrm{T}_{4^{-}}$and aortic constriction-induced cardiac hypertrophy found that the protein expression of the PKC $\varepsilon$ was downregulated in the $\mathrm{T}_{4}$-induced cardiac hypertrophy, whereas $\mathrm{PKC} \varepsilon$ protein expression was not decreased in hearts with aortic banding-induced cardiac hypertrophy. Similarly, in the present study, PKCE protein expression was found to be downregulated in the THYR as compared with NORM hearts, whereas in the THYRacute hearts it was similar to NORMacute hearts. Furthermore, PKC $\varepsilon$ protein expression was similar in hearts from HYP and SOP rats. This differential pattern of PKC $\varepsilon$ protein expression that is observed in hearts with $\mathrm{T}_{4^{-}}$and aortic banding-induced hypertrophy seems to be identical to the pattern of activation of $\mathrm{p} 38$ MAPK that occurs in response to ischaemia. Thus, it could be suggested that in long-term $\mathrm{T}_{4}$-treated hearts the observed reduction of p38 MAPK activity might be the result of the decreased PKCE activation corresponding to the reduced PKCE protein expression. However, in the present study, we did not measure the activity of PKC $\varepsilon$. Further studies are needed to elucidate the underlying mechanisms of the attenuated p38 MAPK activation induced by ischaemia in long-term $\mathrm{T}_{4}$-treated hearts.

It is apparent that the induction of HSP70 mRNA expression and the activation of $\mathrm{p} 38$ MAPK in response to ischaemic stress is altered after chronic $\mathrm{T}_{4}$ administration. However, the biological significance of this response is not known. In normal hearts, increased HSP expression has been found to confer cardioprotection against ischaemic insult (Marber et al. 1995, Suzuki et al. 1997). Furthermore, decreased activity of the p38 MAPK has been shown to reduce apoptosis and to protect the cell from lethal ischaemic stress (Zechner et al. 1998, Ma et al. 1999, Mackay \& Mochly-Rosen 1999, Barancik et al. 2000). However, further work is needed to clarify the role of the HSPs and the p38 MAPK in the adaptive response of the hyperthyroid heart to ischaemia. Hyperthyroid hearts, as this study shows in accordance with previous reports (Buser et al. 1990, Pantos et al. 1999, 2000), have increased tolerance to ischaemia regardless of the development of cardiac hypertrophy and the decreased thermodynamic efficiency. Moreover, it has been recently reported that subclinical hypothyroidism is an independent risk factor for myocardial infarction in elderly women (Hak et al. 2000) and lower levels of $\mathrm{T}_{3}$ are associated with greater severity of acute myocardial infarctions (Kimura et al. 2000).

In conclusion, long-term $\mathrm{T}_{4}$ administration increases HSP70 mRNA induction and attenuates p38 MAPK activity in response to ischaemia. The biological significance of this adaptive response remains to be elucidated.

\section{Acknowledgements}

This research work has been supported by the University of Athens and Bodosakis Institution research funds.

\section{References}

Barancik M, Htun P, Strohm C, Kilian S \& Shaper W 2000 Inhibition of the cardiac p38-MAPK pathway by SB203580 delays ischaemic cell death. Journal of Cardiovascular Pharmacology 35 474-483.

Benjamin IJ, Horie S, Greenberg ML, Alpern RJ \& Williams RS 1992 Induction of stress proteins in cultured myogenic cells. Molecular signals for the activation of heat shock transcription factor. Journal of Clinical Investigation 89 1685-1689.

Bogoyevitch MA 2000 Signalling via stress-activated mitogen-activated protein kinases in the cardiovascular system. Cardiovascular Research 45 826-842.

Bogoyevitch MA, Gillespie-Brown J, Ketterman AJ, Fuller SJ, Ben-Levy R, Ashworth A, Marshall CJ \& Sugden PH 1996 Stimulation of the stress-activated mitogen-activated protein kinase subfamilies in perfused heart. p38/RK mitogen-activated protein kinases and c-jun N-terminal kinases are activated by ischaemia/ reperfusion. Circulation Research 79 162-173.

Buser PT, Wikman Coffelt J, Wu ST, Derugin N, Papmley WW \& Higgins CB 1990 Postischemic recovery of mechanical performance and energy metabolism in the presence of left ventricular hypertrophy. A 31P-NMR study. Circulation Research 66 735-746.

Chomczynsky P \& Sacchi N 1987 Single step method of RNA isolation and acid guanidinium thiocyanate-phenol-chloroform extraction. Analytical Biochemistry 162 156-159.

Cook SA, Sugden PH \& Clerk A 1999 Activation of c-Jun Nterminal kinases and $\mathrm{p} 38$-mitogen-activated protein kinases in human heart failure secondary to ischaemic heart disease. Journal of Molecular and Cellular Cardiology 31 1429-1434.

Fryer LGD, Holness MJ, Decock JB \& Sugden MC 1998 Cardiac protein kinase $\mathrm{C}$ expression in two models of cardiac hypertrophy associated with an activated cardiac renin-angiotensin system: effect of experimental hyperthyroidism and genetic hypertension (the mRen-2 rat). Journal of Endocrinology 158 27-33.

Gray C, Amrani M \& Yacoub M 1999 Heat stress proteins and myocardial protection: experimental model or potential clinical tool? International Journal of Biochemistry and Cell Biology 31 559-573.

Grofte T, Wolthers T, Moller N, Jorgensen JO, Flyvbjerg A, Orskov H \& Vilstrup H 1997 Moderate hyperthyroidism reduces liver amino nitrogen conversion, muscle nitrogen contents and overall nitrogen balance in rats. European Journal of Clinical Investigation $\mathbf{2 7}$ $85-92$.

Hak AE, Pols H, Visser TJ, Drexhage HA, Hofman A \& Witteman JCM 2000 Subclinical hypothyroidism is an independent risk factor for atherosclerosis and myocardial infarction in elderly women: The Rotterdam Study. Annals of Internal Medicine 132 270-278.

Hamasaki Y, Shinohara O, Ishida H, Hayashi Y \& Nakazawa H 2000 Decreased protein kinase C-epsilon expression in hypertrophied cardiac ventricles induced by triiodothyronine treatment in the rat. Life Sciences 67 1859-1868.

Hoh JFY \& Egerton JL 1979 Action of triiodothyronine on the synthesis of rat ventricular myosin isoenzymes. FEBS Letters 101 143-146.

Jalili T, Takeishi Y \& Walsh RA 1999 Signal transduction during cardiac hypertrophy: the role of Gaq, PLC Bi, and PKC. Cardiovascular Research 44 5-9.

Kimura T, Kanda T, Kotajima N, Kuwabara A, Fukumura Y \& Kobayashi I 2000 Involvement of circulating interleukin-6 and its receptor in the development of euthyroid sick syndrome in patients with acute myocardial infarction. European Journal of Endocrinology 143 179-184.

Klein I 1980 Thyroid hormone and the cardiovascular system. American Journal of Medicine 88 631-637.

Kukreja RC, Kontos MC, Loesser KE, Batra SK \& Qian YZ 1994 Oxidant stress increases heat shock protein $70 \mathrm{mRNA}$ in isolated perfused rat heart. American Journal of Physiology 267 H2213H2219. 
Ma XL, Kumar S, Gao F, Louden CS, Lopez BL, Christopher TA, Wang C, Lee JC, Feuerstein GZ \& Yue TL 1999 Inhibition of p38 mitogen-activated protein kinase decreases cardiomyocyte apoptosis and improves cardiac function after myocardial ischemia and reperfusion. Circulation 99 1685-1691.

Mackay K \& Mochly-Rosen D 1999 An inhibitor of p38 mitogenactivated protein kinase protects neonatal cardiac myocytes from ischemia. Journal of Biological Chemistry 274 6272-6279.

Marber MS, Mestril R, Chi SH, Sayen MR, Yellon DM \& Dillman WH 1995 Overexpression of the rat inducible $70 \mathrm{kDa}$ heat stress protein in a transgenic mouse model increases the resistance of the heart to ischaemic injury. Journal of Clinical Investigation $\mathbf{9 5}$ 1446-1456.

Moalic JM, Bauters C, Himbert D, Bercovici J, Mouas C, Guicheney P, Baudoin-Legros M, Rappaport L, Emanoil-Ravier R, Mezger V \& Swynghedauw B 1989 Phenylephrine, vasopressin and angiotensin II as determinants of proto-oncogene and heat shock protein gene expression in adult rat heart and aorta. Journal of Hypertension 7 195-201.

Myrmel T, McCully JD, Malikin L, Krukenkamp IB \& Levitsky S 1994 Heat shock protein 70 mRNA is induced by anaerobic metabolism in rat hearts. Circulation 90 II299-II305.

Nagarkatti DS \& Shaafi RI 1998 Role of p38 MAP kinase in myocardial stress. Journal of Molecular and Cellular Cardiology 30 $1651-1664$

Nitta Y, Abe K, Aoki M, Ohno I \& Isoyama S 1994 Diminished heat shock protein $70 \mathrm{mRNA}$ induction in aged rat hearts after ischaemia. American Journal of Physiology 267 H1795-H1803.

Pantos CI, Davos CH, Carageorgiou HC, Varonos DV \& Cokkinos DV 1996 Ischaemic preconditioning protects against myocardial dysfunction caused by ischaemia in isolated hypertrophied rat hearts. Basic Research in Cardiology 91 444-449.

Pantos C, Cokkinos DD, Tzeis S, Malliopoulou V, Mourouzis I, Carageorgiou H, Limas C, Varonos D \& Cokkinos D 1999 Hyperthyroidism is associated with preserved preconditioning capacity but intensified and accelerated ischaemic contracture in rat heart. Basic Research in Cardiology 94 254-260.

Pantos C, Mourouzis I, Tzeis S, Malliopoulou V, Cokkinos DD, Asimakopoulos P, Carageorgiou H, Varonos DD \& Cokkinos DV
2000 Propranolol diminishes cardiac hypertrophy but does not abolish acceleration of the ischemic contracture in hyperthyroid hearts. Journal of Cardiovascular Pharmacology 36 384-389.

Pantos C, Tzilalis V, Giannakakis S, Cokkinos DD, Tzeis St, Malliopoulou V, Mourouzis I, Asimakopoulos P, Carageorgiou H, Varonos D \& Cokkinos DV 2001 Phenylephrine induced aortic vasoconstriction is attenuated in hyperthyroid rats. International Angiology (In Press).

Polikar R, Burger AG, Scherrer U \& Nicod P 1993 The thyroid and the heart. Circulation 87 1435-1441.

Suzuki K, Sawa Y, Kaneda Y, Ichikawa H, Shivakura R \& Matsuda H 1997 In vivo gene transfection with heat shock protein 70 enhances myocardial tolerance to ischaemia-reperfusion injury in rat. Journal of Clinical Investigation 99 1645-1650.

Tajima M, Isoyama S, Nitta Y \& Abe K 1997 Attenuation of heat shock protein expression by coronary occlusion in hypertrophied hearts. American Journal of Physiology 273 H526-H533.

Van der Vusse GJ, Coumans WA, Ulrich M \& Van Bilsen M 1998 Thyroxine induced alteration in cardiac energy metabolism. Journal of Molecular and Cellular Cardiology 30 A110.

Walker JM 1994 Basic Protein And Peptide Protocols. Totowa, NJ, USA: Humana Press.

Yaoita H, Ogawa K, Maehara K \& Maruyama Y 2000 Apoptosis in relevant clinical situations; contribution of apoptosis in myocardial infarction. Cardiovascular Research 45 630-641.

Yin T, Sandhu G, Wolfgang CD, Burrier A, Webb RL, Rigel DF, Hai T \& Whelan J 1997 Tissue-specific pattern of stress kinase activation in ischaemic/reperfused heart and kidney. Journal of Biological Chemistry 272 19943-19950.

Zechner D, Craig R, Hanford DS, McDonough PM, Sabbadini RA \& Glembotski CC 1998 MKK6 activates myocardial cell NF-kB and inhibits apoptosis in a p38 mitogen-activated protein kinase-dependent manner. Journal of Biological Chemistry 273 $8232-8239$.

Received 12 February 2001 Accepted 1 March 2001 